\title{
Corrosion of the infrastructure - migrating corrosion inhibitors, "green" bio based technology to extend durability of new and existing infrastructure
}

\author{
Ivana Lipošćak ${ }^{1, *}$, Jessi Meyer ${ }^{2}$, and Boris Mikšić3 \\ ${ }^{1 *}$ Cortec Corporation, Ivana Lučića 5, 10000 Zagreb, Croatia \\ ${ }^{2}$ Cortec Corporation, 4119 White Bear Parkway, St.Paul, MN, 55110, USA \\ ${ }^{3}$ Cortec Corporation, 4119 White Bear Parkway, St.Paul, MN, 55110, USA
}

\begin{abstract}
Corrosion of embedded steel is a leading cause of deterioration in reinforced concrete structures. While concrete mix designs have become more durable, the possibility of cracking due to shrinkage, movement, or other forces is a consideration when designing for long service life. In addition, preserving integrity and extending the useful service life of existing structures is of paramount importance. Migrating, organic corrosion inhibitors have been used for more than 30 years in construction applications as an economical method of corrosion mitigation. Migrating corrosion inhibitors, based on organic amines have become available with the claimed advantage that, as well as being capable of application as admixtures, they may be applied as remedial agents to the surface of the concrete. This paper will give details on the chemistry of organic corrosion inhibitors, test methods used to assess the efficacy of migrating corrosion inhibitors in concrete and their performance in new construction, repair and specialty applications.
\end{abstract}

\section{Introduction}

High performance mix designs have significantly improved the quality of today's concrete. Unfortunately, cracking, whether due to shrinkage, settlement or other forces, is a reality that is never eliminated no matter how good concrete is. The need for a corrosion inhibitor that can provide protection in the presence of minor cracks is very real. In addition, with aging infrastructure, preserving the integrity of structures and extending useful service life is of paramount importance. Surface corrosion inhibitor treatments must be capable of penetrating to the depth of embedded reinforcing steel. Migrating organic corrosion inhibitors meet these challenges in a costeffective manner. They are available in many different forms for all types of construction - admixtures for new concrete; repair mortars and grouts; topical treatments; injectable products; and many specialty formats.

Organic corrosion inhibitors (OCI) are effective against chloride induced corrosion, as well as carbonation and other corrosive elements $(\mathrm{H} 2 \mathrm{~S}, \mathrm{SO} 2$, etc.). Organic corrosion inhibitors (OCI) are aminebased chemicals that possess saturated vapour pressure under atmospheric conditions, thus allowing vapour transport of the inhibitive substance [1]. Concrete and other cementitious materials have pore structures that allow for liquid and vapour diffusion of these chemicals throughout the substrate. When organic inhibitors encounter embedded reinforcing, they have an attraction to it, adsorbing onto the metal surface forming a protective molecular layer.

OCI are a mixed (anodic/cathodic) inhibitor system. The inhibition of the cathodic process is achieved by the incorporation of one or more oxidising radicals in an organic molecule. Inhibitor molecules are hydrolysed in the electrolyte and then adsorbed on the metal surface. The nitrogen of the amine group can enter a coordinate bond with metal (including steel reinforcement) thus enhancing the adsorption process. Adsorption of amines and carboxylates increases the resistivity of metal to corrosion. This molecular layer serves as a buffer to hold the $\mathrm{pH}$ at the interface in the basic regime (above $\mathrm{pH}$ 9) [2].

Organic corrosion inhibitors migrate through the concrete depending on the OCI type and application method. OCI admixtures are readily dispersed in the mixing process and can also migrate to reinforcement by diffusion as both a liquid and a vapour. OCI surface treatments penetrate first as a liquid through capillary suction and then by diffusion [3].

The first generation of OCI was based on amine alcohol technology. The latest generation is based on amine carboxylates. The amine carboxylate technology includes by-products of corn - a renewable resource.

Amine carboxylate based OCI can delay setting time of concrete 3-4 hours at $20^{\circ} \mathrm{C}$. This delay is less pronounced at warmer temperatures. Set delay is a desired side effect in warm weather as less retarder will need to be added to the concrete mix when using OCI. Combining amine carboxylate based organic corrosion inhibitors with some set retarding materials (admixtures) may create increased setting times, but generally no other concrete properties are affected. In cases where set delay is not desired, normal set (NS) versions of OCI have been developed, or non-chloride accelerators can be used.

\section{Chemistry of organic corrosion inhibitors}

\footnotetext{
Corresponding author: iliposcak@cortecvci.com
} 
Corrosion inhibitors are classified based upon the part of the corrosion cell that they affect. Organic corrosion inhibitors are classified as mixed inhibitors, meaning they affect both anodic and cathodic portions of the corrosion cell. These inhibitors adsorb onto metal, forming a protective molecular layer on steel surfaces. This film prevents corrosive elements from further reacting with embedded reinforcement and reduces existing corrosion rates. Adsorption of the inhibitor takes place via its polar functional group anchored to the metal while the non-polar or hydrophobic chain is oriented perpendicularly to the metal surface. The hydrophobic chains not only repel aqueous corrosive fluids but interact with each other to form aggregates thereby forming a tight film on the metal surface [2]. Figures 1 and 2 illustrate adsorption of amine alcohol and amine carboxylate organic inhibitors respectively.

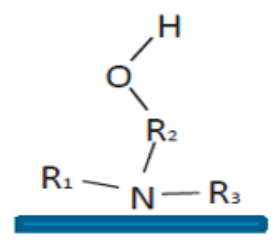

Fig. 1. Illustration of Amine Alcohol Inhibitor, where R1,2,3 is $\mathrm{H}$ or alkyl group, $\mathrm{OH}$ tail end group

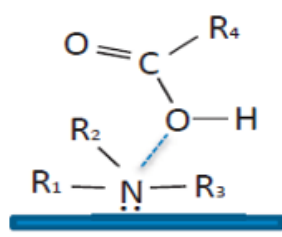

Fig. 2. Illustration of Amine Carboxylate Inhibitor, where $\mathrm{R} 1,2,3$ is $\mathrm{H}$ or alkyl group, $\mathrm{OH}$ tail end group

Organic migrating corrosion inhibitors reach embedded reinforcement in several ways. First, the inhibitor is dispersed through the concrete with adequate mixing. The transportation of OCI within concrete then occurs via infiltration through concrete pore capillary networks. Thirdly, due to their relatively high vapour pressures, OCI move via diffusion in a gaseous state through the pore network and minor cracks. Finally, when the molecules meet embedded metals, they have a specific attraction (as described above) to it. The molecules move randomly from areas of high concentration to areas of low concentration until equilibrium is reached (Fick's 2nd Law of Diffusion). Because of the final adsorption of OCI on embedded metal, the concentration gradient drives OCI to move towards the metal. X-Ray Photoelectron Spectroscopy (XPS) analysis has demonstrated the nitrogen rich layer (from amine moiety in OCI molecules) formed on rebar surfaces embedded in concrete that received a topical treatment of OCI. This protective, monomolecular layer also reduces the corrosion rate $[4,5]$. Amine alcohols differ from amine carboxylates in their tail end group. As can be seen in Figures 1 and 2 above, the amine alcohols contain an $\mathrm{OH}$ terminal group at the tail end, whereas amine carboxylates have no such hydrophilic terminal group. The exposed $\mathrm{OH}$ group on amine alcohols makes it available to interact with water-based electrolyte near the rebar. This means that the amine alcohol film could more easily desorb from the metal surface compared to the amine carboxylate film and allow corrosive species (such as chlorides) to attack the metal. As a result, the amine carboxylate based OCI by nature have a more tenacious bond to the metal surface [2]. The strength of the bond between the OCI molecule and the rebar is what delays the onset of corrosion and reduces corrosion rates compared to a control once initiated. With amine alcohols, we typically see a slight extension in time to corrosion initiation, and corrosion currents cut in half compared to a control following corrosion initiation. With amine carboxylates, we typically see a double to tripling in time to corrosion initiation, and once corrosion starts, rates are reduced by 5-15 times compared to a control [6].Another small effect amine carboxylates have is that as they migrate through the concrete, some of them will react with calcium hydroxide to form calcium carboxylate $/ \mathrm{Ca}(\mathrm{COO}) 2$, an insoluble salt, which effectively blocks some of the pores, making future ingress of chlorides and other contaminants more tortuous [7].

There are many test methods used to assess the efficacy of migrating corrosion inhibitors in concrete. It is important to note that these tests are described by category - corrosion protection, migrating ability, film forming ability, and compatibility with other materials.

\subsection{Assessment of Corrosion Protection}

The most widely used test method for evaluating concrete corrosion inhibiting admixtures is ASTM C1582 / C1582M - Standard Specification for Admixtures to Inhibit Chloride-Induced Corrosion of Reinforcing Steel in Concrete [8]. This standard consists of two components. The first is an evaluation of how the corrosion inhibitor affects concrete properties such as setting time, air entrainment, compressive and flexural strengths, freeze thaw resistance, and length change. The second component involves corrosion testing according to ASTM G109Standard Test Method for Determining Effects of Chemical Admixtures on Corrosion of Embedded Steel Reinforcement in Concrete Exposed to Chloride Environments [9] or ASTM G180 - 13, Standard Test Method for Corrosion Inhibiting Admixtures for Steel in Concrete by Polarization Resistance in Cementitious Slurries [10]. ASTM G109 test samples can be seen in Figure 3 below. The test consists of casting concrete

\footnotetext{
*Corresponding author: iliposcak@cortecvci.com
} 
blocks containing a triangular arrangement of rebar embedded within them - one bar on top and two on the bottom. These samples are then exposed to cyclic wetting and drying cycles with salt water, and the macrocell current between the top bar and bottom two bars is monitored and recorded every 4 weeks ( 4 weeks $=$ one cycle). The testing stops once the total integrated macrocell current reaches 150 Coulombs.
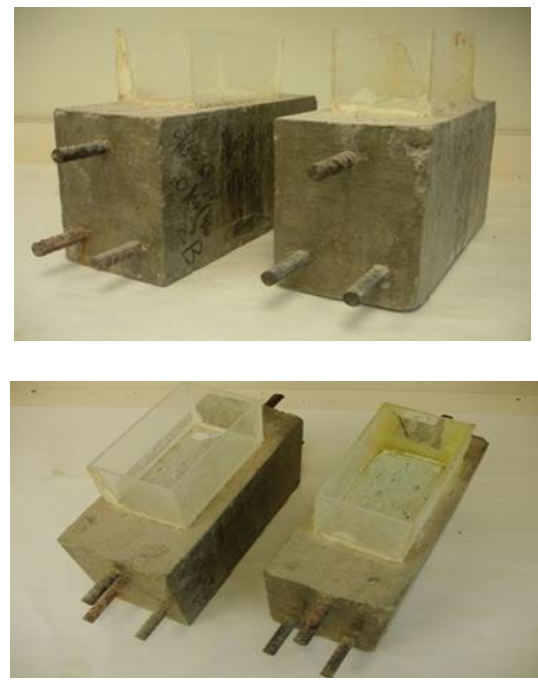

Fig. 3. Example of ASTM G109 Test Blocks

The ASTM G180 - 13 [10] test method provides a means for assessing corrosion-inhibiting concrete admixtures in a filtered cementitious liquid. Compared with a testing period of up to a few years required by ASTM G 109, this test method provides results within a few days. In this test, the polarization resistance of a steel sample is measured by applying a current through the test solution while varying the voltage. According to ASTM C1582, an admixture is behaving as a corrosion inhibitor when using the G180 Test Method (using $0.5 \mathrm{M} \mathrm{NaCl}$ with four control and four test specimens) if the mean $1 / \mathrm{Rp}$ value is less than or equal to $1 / 8$ the control average. Poor performance in G180 requires additional testing to determine if the admixture improves corrosion resistance.

Electrochemical Impedance Spectroscopy (EIS) is a powerful, rapid and accurate non-destructive method for the evaluation of a wide range of materials including coatings, anodised films and organic corrosion inhibitors on metal surfaces [11]. During EIS experiments, a small amplitude AC signal is applied to the metal system being studied. Data from EIS can provide detailed information on corrosion rate, electrochemical mechanisms, reaction kinetics, and detection of localised corrosion in a system.

In addition to the above standard tests, ASTM G109 is frequently modified to make it more aggressive so results can be seen faster. These tests are generally referred to as a Modified ASTM G109 or a cracked beam test. In a cracked beam test, test samples are created in the same manner as the ASTM G109 standard shown above, but the beams are cracked in a controlled way (saw cut and application of flexural stress) prior to salt water cycling to make the test more aggressive. Other modifications include changing the $\mathrm{NaCl}$ (salt) concentration (increasing from 3.5\% to 6\%) as well as the cycle times (adjusting from 4 weeks down to as little as 1-week cycles). Another variation on ASTM G109 is permanent immersion of concrete beams in salt water instead of using ponding cycles.

The most recent test for evaluating organic corrosion inhibitors in repair applications is the U.S. Bureau of Reclamation M-82 - Standard Protocol to Evaluate the Performance of Corrosion Mitigation Technologies in Concrete Repairs (USBR M-82) [12]. The protocol covers two methods for measuring and differentiating the performance of reinforcing steel corrosion mitigating techniques for concrete repairs caused by damage due to chloride ingress. This protocol doesn't differentiate between active and passive corrosion, but it has all of the positive aspects of impedance testing (described in EIS above) but on a larger scale which is more representative of slabs in the field [13].

\subsection{Assessment of Migrating Ability}

Migration of OCI materials into concrete can be evaluated using UV Spectroscopy. This method allows us to detect OCI presence at various depths of concrete by analysing sliced core samples. OCIs are visible in the UV range. By extracting powdered concrete in deionised water, and measuring the extract using UV spectroscopy, the presence of OCI in concrete can be detected. This is done by comparing the absorbance values from treated concrete against the absorbance values of untreated concrete at specific wavelengths. While initial results are only qualitative, if a calibration curve is created with known doses of OCI, the actual concentration can be more accurately determined.

\subsection{Assessment of Film Forming Ability}

The film forming ability of OCIs can be measured using Scanning Electron Microscopy (SEM) and X-ray Photoelectron Spectroscopy (XPS). SEM is microscopy that produces images of a sample by scanning it with a focused beam of electrons. The electrons interact with atoms in the sample, producing various signals that can be detected and contain information about the sample's surface composition and topology. The presence of OCI, or the lack of it, on metal surfaces can thus be detected.

XPS is a spectroscopic technique in which a beam of X-rays is focused onto the surface of a material and as the beam bounces off the surface it is received by an electron collection device. The data received is then

\footnotetext{
*Corresponding author: iliposcak@cortecvci.com
} 
analysed to determine the elemental composition of the material which reflected the $\mathrm{x}$-ray beam.

In terms of organic, migrating corrosion inhibitors XPS detection can be used to analyse a sample of rebar to determine if there is inhibitor on the surface. Both amine alcohols and amine carboxylates are nitrogen containing compounds which is not found in abundance in the concrete matrix. Therefore, nitrogen levels (relative concentration when comparing two plots, i.e. control vs. treated) recorded on the XPS spectrogram can be used to determine if corrosion inhibitor has migrated to the depth of the rebar. XPS also has the capability to look at the depth at which an element is from the surface of the steel, so the spectrogram can be used to determine depth at which the corrosion inhibitor adsorbed into the rebar in comparison to other elements like chloride.

\section{References}

\subsection{New construction applications}

In new construction, OCI are incorporated into concrete as an admixture, either by adding to the mix water at a ready mix plant, or by adding on the jobsite to the ready mix truck prior to pouring. Their dosage rate is independent of the expected chloride levels. The recommended dosage rate is a sufficient concentration of inhibitor to form a monomolecular film on embedded metals and is independent of chloride concentrations. Unlike anodic inhibitors such as calcium nitrite, OCI do not have a "dangerous" concentration level - situations where a lower than required dosage rate relative to chloride content concentration would promote pitting corrosion. The latest generation of OCI admixtures, based on amine carboxylates, are certified to meet NSF/ANSI 61 2016 Drinking Water System Components -Health Effects requirements, meaning they are safe for use at their recommended dosage rates in structures containing potable water. These corrosion inhibitors also contain renewable resources as raw materials one of the corrosion inhibiting materials in the amine carboxylate admixtures is derived from corn. They have been tested to ASTM C1582 / C1582M Standard Specification for Admixtures to Inhibit Chloride-Induced Corrosion of Reinforcing Steel in Concrete and pass the requirements for both physical property effects on concrete as well as for corrosion inhibition capability.

\subsubsection{Randolph Avenue Bridge}

One of the oldest applications of OCI admixtures was a bridge deck overlay done 32 years ago on the Randolph Avenue Bridge which spans Interstate 35E in St. Paul, $\mathrm{MN}$. The bridge is located in an area where winters are severe and de-icing salts are heavily used to combat icy road conditions. Originally built in 1963, the deck underwent repair in 1986 to mitigate chloride induced corrosion of the reinforcing steel and spalling that was occurring. Repair involved removing deteriorated concrete and milling to within $13 \mathrm{~mm}$ of embedded reinforcement. The deck was then replaced with a low slump, dense concrete (LSDC) overlay. Depth of the overlay varied from 58 to $107 \mathrm{~mm}$, with the top layer of reinforcing steel located at $76 \mathrm{~mm}$ depth. Mix design parameters for the overlay were: Type I Cement, W/C Ratio 0,32, with Water-Reducing admixtures, AirEntraining Agent and OCI. An amine alcohol based OCI admixture was added to the overlay for the two westbound traffic lanes at a rate of $0.6 \mathrm{1} / \mathrm{m} 3$. The two eastbound traffic lanes used the same mix design without the corrosion inhibitor, to act as a control.

Chloride contents readings indicate that the chloride levels in the control side were higher than the treated side and that they have continued to rise at the depth of the steel over time.

Corrosion current readings, Figure 4, have increased on both sides of the bridge over time. Readings taken in July of 2011 showed that the control side had entered into active corrosion levels (corrosion rate readings above $0.5 \mu \mathrm{A} / \mathrm{cm} 2$ ). All three sections tested indicated readings in the active corrosion range with the highest rate of corrosion recorded in the centre section of the control side, with an average reading of $1.27 \mu \mathrm{A} / \mathrm{cm} 2$. In comparison, all three sections of the control side had readings in the passive range (corrosion rate readings less than $0.5 \mu \mathrm{A} / \mathrm{cm} 2$ ), with the highest being the centre section with an average reading of $0.42 \mu \mathrm{A} / \mathrm{cm} 2$, indicating the treated side had roughly $67 \%$ lower rates than the untreated areas.

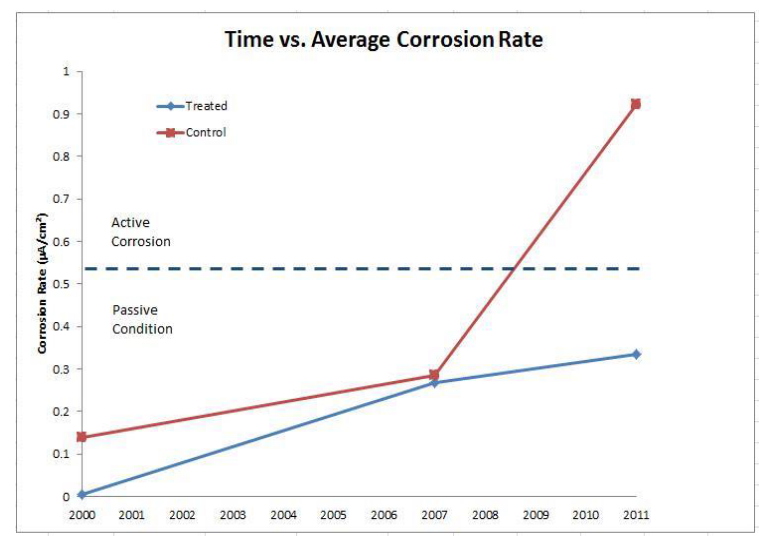

Fig 4. Randolph Avenue Bridge Average Corrosion Rates

\subsection{Specialty and repair applications}

OCI inhibitors have also been developed to help with corrosion issues in unique construction environments. Use of powder based OCI inhibitors on post tensioned structures has been occurring for more than 10 years to provide temporary protection to PT cables prior to grouting. Some researchers confirmed that the powder based OCI fogged into PT cable construction provided a significant reduction in corrosion compared to control 
samples in long term laboratory-based corrosion studies (one year of saltwater exposure) and that the OCI did not significantly affect the bond of grout injected after their application. Based on this data and additional research, a novel use of OCI was created for the Severn Bridge Structure in the United Kingdom.

\subsubsection{Severn Bridge, United Kingdom}

The Severn Bridge is a $988 \mathrm{~m}$ span suspension bridge over the Severn River between Bristol and South Wales [37]. Inspections found that the PT cables were corroded and had reduced structural strength. Following this investigation, an acoustic monitoring system and dry air injection system were installed on both main suspension cables to control the deterioration. The purpose of the dry air injection system was to reduce the relative humidity $(\mathrm{RH})$ within the cables to $<40 \%$, an accepted percentage to prevent corrosion of metals [14].

To provide additional corrosion protection to the PT cable wires during the initial period of moisture reduction-when corrosion rates could increase as oxygen became more available - and to provide a back-up if the dehumidification system went out of service (i.e. for maintenance), an organic corrosion inhibitor system was developed for introduction into the dry air stream. Concerns over fogged OCI powders blocking air voids in the cables, water-based systems being unsuitable when looking for moisture reduction to reduce corrosion rate, and solvent based systems being incompatible with the cable wrap and $\mathrm{RH}$ probes, meant a different approach had to be used in development of the OCI.

For these reasons, a powder version OCI, contained in a vapour permeable pouch, was developed to introduce pure inhibitor vapour into the system using the dehumidification air stream as the carrier. This ensured a sufficient level of inhibitor would be present within the air voids to protect exposed metal surfaces while avoiding the risks of blockage by solid or liquid material. Because the protective inhibitor layer is at a molecular level, it has no influence on clearances and had only a minimal effect on other physical properties. Testing showed that use of the inhibitor caused a small increase in wire-to-wire friction at low contact pressure and no significant frictional effect at higher loads. Further testing was carried out to confirm the inhibitor would not adversely affect other components in the system; including; cable wraps, sealants, and probes.

The OCI system manufacturer also developed an inhibitor detection kit. This detection method is used in ongoing field inspections to ensure presence of the inhibitor.

The consulting engineers for the project also developed monitoring criteria and systems for future management of the bridge to comply with the principals in the British BD79/13 Standard - The Management of Sub-standard Highway Structures.
This involves visual inspections by bridge operators who record any observations that may be relevant to the condition of the cables.

\section{Conclusions}

Organic corrosion inhibitors (OCI) have been used in the construction industry for more than 30 years. OCI are made from a renewable raw material and its effectiveness has been demonstrated on many types and ages of construction. OCI Admixtures have been tested to meet the requirements of ASTM C1582 Standard Specification for Admixtures to Inhibit Corrosion in Chloride Exposed Environments and have demonstrated their ability to significantly increase expected service life of structures with a single application during construction.

OCI surface treatments used for repair have also been tested extensively and shown to reduce corrosion rates significantly even in the presence of existing chlorides and carbonation. Long term study on repair projects has demonstrated their ability to extend the useful life of existing structures.

Finally, use of OCI is not limited to concrete admixtures or surface treatments, but can also be done in applications as seen on the post tensioned tendons and cable ducts of the post tensioned and suspension structures.

Sustainable construction has become a goal for owners across the globe. Often overlooked aspect is the durability and service life of the final structure. However, OCI are undoubtedly one of the main future factors influencing structural sustainability.

\section{References}

1. B.A. Miksic, Use of vapor phase inhibitors for corrosion protection of metal products, Corrosion, 83, Paper No. 308, NACE, Houston, (1983).

2. B.A Miksic, Improving the durability of infrastructure with migratory corrosion inhibitors (MCI) handbook, Cortec Corporation, St Paul, (2014).

3. D. Bjegovic, L.Sipos, V.Ukrainczyk, et,al., Diffusion of the MCI 2020 and 2000 corrosion inhibitors into concrete, In:Swamy $\mathrm{R} N \mathrm{Ed}$, Proceedings of Steel in Concrete, Sheffield, Academic Press, 865-877, (1994).

4. B. Bavarian and L. Reiner, Current progress in corrosion inhibition of reinforcing steel in concrete using migrating corrosion inhibitors, Corrosion 2006, Paper No. 06347, San Diego, NACE, (2006).

5. V.A. Zarenin and A.B. Ostrovski, MCI-2000 Diffusion Rate Testing Report, Moscow, Institute for Corrosion Protection Russian Federation, (1993).

6. T. Suess and R Stehly, Report of Corrosion Inhibitor Testing AET Job No. 05-00021, St. Paul, American Engineering and Testing, (2002). 
7. A. Rudy and L.Wachowski, ASTM E96 (2005) Standard Test Methods for Water Vapor Transmission of Materials. TCG Project No. 09146, Kalamazoo, Tourney Consulting Group, (2010).

8. ASTM International, ASTM C1582 / C1582M-11, Standard Specification for Admixtures to Inhibit Chloride-Induced Corrosion of Reinforcing Steel in Concrete [Internet]. West Conshohocken, PA: ASTM International; (2011) (updated 2011 July 1; cited 2017 June 26). Available from: www.astm.org

9. ASTM International, ASTM G109-07(2013), Standard Test Method for Determining Effects of Chemical Admixtures on Corrosion of Embedded Steel Reinforcement in Concrete Exposed to Chloride Environments [Internet]. West Conshohocken, ASTM International; 2011 [updated 2013 May 1; cited 2017 June 26]. Available from: www.astm.org

10. ASTM International. ASTM G180-13, Standard Test Method for Corrosion Inhibiting Admixtures for Steel in Concrete by Polarization Resistance in Cementitious Slurries [Internet]. West Conshohocken, ASTM International; 2011 (updated 2013 May 1; cited 2017 June 26). Available from: www.astm.org

11. A Furman, L. Austin, Measurement of Electrochemical Impedance of Concrete Samples. Cortec Test Method CC-022. St. Paul, Cortec Corporation, (2016).

12. United States Department of the Interior Bureau of Reclamation, M-82 (M0820000.714), Standard Protocol to Evaluate the Performance of Corrosion Mitigation Technologies in Concrete Repairs. Denver, July 2014. (cited 2017 June 26). Available from: www.usbr.gov/tsc/techreferences/mands/mandspdfs/StandardCorrosionProtocol_07-2014rev082016_508.pdf

13. M Shen., C Heurung., et. al., Mitigating corrosion of concrete steel reinforcement with surface treatments containing migrating corrosion inhibitors, Concrete Service Life Extension Conference, Paper No. W15, Orlando, NACE; (2016).

14. P Lambert. and J Fisher., Corrosion control of the Severn Bridge main suspension cables, Materials Performance, 53, 11, 2-7, (2014).

\footnotetext{
*Corresponding author: iliposcak@cortecvci.com
} 